\title{
Quantitative textural analysis of Vulcanian pyroclasts (Montserrat) using multi-scale X-ray computed microtomography: comparison with results from 2D image analysis
}

T. Giachetti 1, A. Burgisser 2, L. Arbaret 2, T.H. Druitt 3,4,5, K. Kelfoun 3,4,5.

1 GEOLAB, 4, rue Ledru, 63057 CLERMONT-FERRAND cedex 1 (France)

2 Institut des Sciences de la Terre d'Orléans

Université d'Orléans,

$1 \mathrm{~A}$, rue de la Férollerie

45071 Orléans Cedex 2 (France)

3 Clermont Université, Université Blaise Pascal, Laboratoire Magmas et Volcans, BP 10448,

F-63000 CLERMONT-FERRAND

4 CNRS, UMR 6524, LMV, F-63038 CLERMONT-FERRAND

5 IRD, R 163, LMV, F-63038 CLERMONT-FERRAND

Corresponding author

Thomas Giachetti

GEOLAB

4, rue Ledru

63057 CLERMONT-FERRAND cedex 1

thomas.giachetti@ univ-bpclermont.fr 


\section{Abstract}

X-Ray computed microtomography was carried out on four pyroclasts from the 1997 Vulcanian explosions of Soufrière Hills Volcano, Montserrat. For the first time, 3D data from multiple image stacks with different spatial resolutions (including a very high spatial resolution of $0.37 \mu \mathrm{m} \cdot \mathrm{px}^{-1}$ ) were combined to perform vesicle and crystal size distributions from $\sim 2 \mu \mathrm{m}$ to $\sim 1 \mathrm{~mm}$ in diameter. Vesicle number densities range from $6.6 \times 10^{14} \mathrm{~m}^{-3}$ in the breadcrust bomb to $59.8 \times 10^{14} \mathrm{~m}^{-3}$ in pumices. Size distributions are invariably power-law for vesicles $>20 \mu \mathrm{m}$, indicating of the importance of bubble coalescence, as supported by visual observation. Minimum Fe-Ti oxides number densities are $12-19 \times 10^{14} \mathrm{~m}^{-3}$, and greatly exceed vesicle number densities. Results are in good qualitative and quantitative agreements with those obtained on the same samples using classical 2D textural image-analysis, and total vesicularities are consistent with those obtained by He-pycnometry.

The coalescence process was investigated using throat size distributions. Coalescence occurred in all pyroclasts between neighbouring bubbles of any sizes; the larger the vesicle, the more connected it is. Coalescence thus affected indifferently pre- and syn-explosive bubbles, suggesting that the syn-explosive gas was rapidly connected to large-scale pathways through which it could escape. This process was largely facilitated in the pumices due to the small thickness of vesicle walls.

Keywords: X-ray computed microtomography, Vesicle Size Distribution, Vulcanian explosions, Soufrière Hills volcano, Coalescence 


\section{Introduction}

Explosive volcanic eruptions are triggered by the fragmentation of magmatic foam into a suspension of pyroclasts and gas that is discharged at high velocities into the atmosphere. The extent and intensity of this fragmentation is mainly dependent on the ability of gas to escape out of the magma, and hence on the processes of gas bubble nucleation, growth and coalescence. Studies of pyroclast textures, mainly performed using 2D imageanalysis, have advanced understanding of these processes (Klug and Cashman 1994, 1996; Klug et al. 2002; Adams et al. 2006; Giachetti et al. in press, and references therein), but several questions remain. One important issue concerns the timing of bubble coalescence relative to fragmentation and eruption, which directly controls permeability acquisition and therefore the ability of magma to outgas during ascent (e.g. Eichleberger et al. 1986; Saar and Manga 1999; Gardner 2007; Gonnerman and Manga 2007; Namiki and Manga 2008 and reference therein). Bubble coalescence is a key process in the determination of eruptive style but is difficult to study, especially in two dimensions.

$\mathrm{X}$-ray computed microtomography $(\mu \mathrm{CT})$ is a powerful, non-destructive method for imaging textures and for quantifying vesicle spatial relationships and size distributions in 3D. Nevertheless, only a few studies of volcanic pyroclasts using this tool are available at the time of writing (Song et al. 2001; Shin et al. 2005; Polacci et al. 2006; Polacci et al. 2008; Polacci et al. 2009a, b; Degruyter et al. 2009). These studies have however demonstrated the power of $\mu \mathrm{CT}$ in the understanding of complex textures, such as those of pyroclasts produced during explosive eruptions. In the present study, $\mu \mathrm{CT}$ was applied to four texturally different samples from the 1997 Vulcanian explosions of Soufrière Hills Volcano, Montserrat. The general features of these explosions were documented by Druitt et al. (2002) and Formenti et al. (2003), and modelled by Clarke et al (2002) and Melnik and Sparks (2002). The pre-explosive conduit stratigraphy and dynamics were reconstructed by Melnik and Sparks (2002), Kennedy et al. (2005), Diller et al. (2006), Clarke et al. (2007) and Burgisser et al. (submitted). A 
detailed 2D textural study of these same samples, including high-resolution vesicle and crystal size distributions, was carried out by Giachetti et al. (in press). Consequently, both the general eruptive dynamics and vesiculation processes during these explosions are well constrained. This context provides a unique chance to compare the results of textural analysis obtained by two methods (2D and 3D image-analysis), applied on the same samples. Moreover, $\mu \mathrm{CT}$ allows investigation of the coalescence process in three dimensions that is impossible to perform in a quantitative way using classical 2D images-analysis techniques.

We first recall the major features of the 1997 explosions and summarise the results of Giachetti et al. (in press) concerning the vesicle size distributions and vesiculation processes occurring before and during a typical Vulcanian explosion. We then describe the acquisition of the microtomographic images, and explain the methodology used to calculate the size distributions of vesicles and crystals larger than $\sim 2 \mu \mathrm{m}$. We emphasize the novelty of our study and compare the results of our 3D textural analysis with those obtained in $2 \mathrm{D}$ by Giachetti et al. (in press) on the same samples, and discuss the relative merits of the two methods. Finally, we investigate the bubble coalescence process, quenched in progress, by estimating throat size distributions and vesicle interconnectivities, and we discuss implications of our results for the processes of magma vesiculation during the 1997 explosions.

\section{Volcanic context and previous results}

The 88 Vulcanian explosions of Soufrière Hills in 1997 occurred every 3-63h (mean of $\sim 10 \mathrm{~h}$ ) in two periods: thirteen between 4 and 12 August, and seventy five between 22 September and 21 October (Druitt et al. 2002). Each started with a high-intensity phase lasting a few tens of seconds during which multiple jets were ejected at $40-140 \mathrm{~m} . \mathrm{s}^{-1}$ (first 10$20 \mathrm{~s}$ ), before collapsing back to form pumiceous pyroclastic flows (Formenti et al. 2003). Fallout of pumice and ash occurred from 3-15-km buoyant plumes that developed above the 
collapsing fountains. A waning phase then followed, lasting 1 to 3 hours. Each explosion discharged on average $8 \times 10^{8} \mathrm{~kg}$ of magma, two-thirds as pyroclastic flows and one-third as fallout, representing a conduit drawdown of 0.5-2 km (Druitt et al. 2002). Studies of quench pressures using microlite or/and glass water contents support a maximum drawdown of $\sim 2$ to $3 \mathrm{~km}$ (Clarke et al. 2007; Burgisser et al. submitted). Each explosion started when magma overpressure exceeded the strength of an overlying degassed plug and a fragmentation wave propagated down the conduit at a few tens of $\mathrm{m}_{\mathrm{s}}{ }^{-1}$ (Druitt et al. 2002; Clarke et al. 2002; Melnik and Sparks 2002; Spieler et al. 2004a-b; Diller et al. 2006; Mason et al. 2006). After each explosion, magma rose up the conduit during the $\sim 10 \mathrm{~h}$ before the onset of a new explosion.

The Vulcanian products are andesitic and contain $\sim 40-50 \mathrm{wt} \%$ of phenocrysts of plagioclase, hornblende, orthopyroxene, magnetite, ilmenite and quartz set in a groundmass consisting of microlites (mostly plagioclase and magnetite) and rhyolitic glass, the total crystal content being 66-90 wt\% (Giachetti et al. in press). The products exhibit a large spectrum of textures including from top to bottom: dense samples and breadcrust bombs from a microlite-rich degassed plug, dense and banded pumices from a transition zone and pyroclastic-flow and fallout pumices derived from a deeper, more homogeneous, gas-rich zone (Burgisser et al. submitted; Giachetti et al. in press).

A detailed textural study of these samples, including high-resolution 2D vesicle and crystal size distributions, was carried out by Giachetti et al. (in press). Vesicles constitute 166 vol\% of breadcrust bombs and $24-79 \%$ of pumices, all those larger than a few tens of $\mu \mathrm{m}$ being interconnected. Small vesicles $(<$ few tens of $\mu \mathrm{m})$ in all pyroclasts are interpreted as having formed syn-explosively, as shown by their presence in breadcrust bombs formed from originally non-vesicular magma. Most large vesicles ( $>$ few hundreds of $\mu \mathrm{m}$ ) in pumices are interpreted as pre-dating explosion, implying pre-explosive conduit porosities up to $55 \%$. About $15 \%$ of large vesicles in pumices, and all those in breadcrust bombs, are angular voids 
formed by syn-explosive fracturing of amphibole phenocrysts. In pumices, an intermediatesized vesicle population formed by coalescence of the small syn-explosive bubbles. Nucleation took place heterogeneously on titanomagnetite, number densities of which greatly exceed those of vesicles. Visual evidence of heterogeneous nucleation exist on SEM images. Bubble growth took place mainly by decompression.

\section{Samples}

Field sampling of the 1997 Vulcanian explosion products was carried out in 2006 and 2008. The interior of one coarsely breadcrusted bomb (BCP1c), two dense pumices (AMO29 and AMO36) and one light pumice (PV3), all from pyroclastic flows deposits, were chosen for $\mu \mathrm{CT}$ analysis of vesicle and crystal size distributions. These samples were chosen because they covered the wide range of textures and vesicularities (from $30 \mathrm{vol} \%$ in the breadcrust bomb interior until more than $75 \%$ in the highly vesicular pumice) observed in the 1997 deposits, and because their vesicle and crystal size distributions have already been measured in 2D (Giachetti et al. in press).

\section{Methods}

X-ray computed microtomography is a powerful, non-destructive method for obtaining information on the texture of a sample, especially the spatial relationships or size distributions of vesicles and crystals. The Vulcanian pyroclasts contain vesicles and crystals spanning several orders of magnitude in size, from $<1 \mu \mathrm{m}$ to several $\mathrm{mm}$ (Giachetti et al. in press). In order to cover this wide range of sizes, $\mu \mathrm{CT}$ images were acquired on each sample at three magnifications, each covering a different size range but with large overlaps.

The largest objects (vesicles and crystals) were imaged using a Skyscan1072 microtomograph at IPROS (Orléans, France). Cylinders of $\sim 10 \mathrm{~mm}$ in diameter were cut into the samples and analysed using a $80 \mathrm{kV}-100 \mu \mathrm{A}$ source. During acquisition, samples were 
rotated 180 degrees around an axis perpendicular to the incident beam, projections being recorded each $0.45^{\circ}$. X-ray projections were then converted to a stack of $1024 \times 1024$ pixels ${ }^{2}$ grey-scale images (Fig. 1a) using the NRecon software. The scale of these images is $\sim 17.36 \mu \mathrm{m} \cdot \mathrm{vx}^{-1}$ ( $\mathrm{vx}=$ voxel that is a cubic pixel) for all the samples. We considered that an object could be detected on the images if it constituted at least 50 voxels $(\sim 2.3$ pixels in diameter), and that it was statistically represented if it measured 0.001 of the analysed sample volume (i.e., 0.1 of the cube side). Considering these limits, objects between $\sim 80 \mu \mathrm{m}$ and $\sim 900 \mu \mathrm{m}$ in diameter were analysed with this set of images, which will be referred to hereon as the IPROS stack.

Intermediate-size objects were analysed at ISTO, Orléans, using a Nanotom microtomograph manufactured by Phoenix|x-ray. Cylinders of $4.5 \mathrm{~mm}$ in diameter were cut from the samples and analysed using a $80 \mathrm{kV}-90 \mu \mathrm{A}$ source. They were rotated through $360^{\circ}$, projections being recorded at each $0.28^{\circ}$, and $1132 \times 1132$ pixels ${ }^{2}$ grey-scale images were obtained by conversion of these projections (Fig. 1b). Image scales from 4 to $8 \mu \mathrm{m}$ (depending on the samples) allowed us to detect objects between $\sim 18 \mu \mathrm{m}$ and $\sim 400 \mu \mathrm{m}$ in diameter on these images, which will be referred to as the ISTO stack.

Objects smaller than a few tens of $\mu \mathrm{m}$ were captured at the Swiss Light Source on the TOmographic Microscopy and Coherent rAdiology experimenTs beamline (TOMCAT, Vilingen, Switzerland). Cylinders of $0.6 \mathrm{~mm}$ in diameter were drilled from each sample and analysed. During acquisition, the samples were rotated $360^{\circ}$, and projections were recorded every $0.24^{\circ}$, then converted online to a stack of 2048 grey-scale images of $2048 \times 2048$ pixels ${ }^{2}$ each (Fig. 1c). The voxel size was $0.37 \mu \mathrm{m}$ for all the samples, rendering analysable objects between $\sim 2 \mu \mathrm{m}$ and $\sim 35 \mu \mathrm{m}$. These images will be referred to as the SLS stack. 


\section{Image analysis}

We treated each stack of images in the same manner. First, we obtained qualitative information about texture by analysing the grey-scale images as sequences in the ImageJ software. Qualitative observations were also made by visualizing 3D renderings of parts of the scans using the commercial software package VGStudio (Fig. 2a-b). We then extracted quantitative information from the same stacks. Since calculation times are large when working with $3 \mathrm{D}$ data, we worked with a texturally representative $300^{3}$ or $400^{3} \mathrm{px}^{3}$ cube, cut from the volume of each stack. We then analysed the images quantitatively using the software packages 3DMA-Rock (Lindquist 1999; Lindquist and Venkatarangan 1999; Lindquist et al. 2000; Prodanovic et al. 2007; Shin et al. 2005) and ImageJ.

For the SLS stack, we first cut a $800^{3} \mathrm{px}^{3}$ cube from the volume, filtered the images in order to highlight thin objects (e.g. glass fibres), and re-sampled the cube by 2 , in order to finally work with a $400^{3} \mathrm{px}^{3}$ cube at a scale of $0.74 \mu \mathrm{m} \cdot \mathrm{vx}^{-1}$. This was done in order to increase the volume analysed without increasing the calculation time, and without losing too many vesicle walls. Images were then segmented (i.e. converted into binary images) using ImageJ in order to distinguish three classes of objects: vesicles, Fe-Ti oxide crystals, and other crystalline phases. Fe-Ti oxides are easy to distinguish on the images, as they usually appear white. The other crystal phases were highlighted on the IPROS and ISTO images, but it was often impossible to distinguish them from residual glass on the SLS images, due to similar grey-levels. Crystal geometrical parameters were then obtained using ImageJ, which provides a list of all 3D objects present in a stack of binary images. To study the vesicle size distribution, we first needed to rebuild some vesicle walls in order to: (1) reconstruct very thin parts that disappeared during the segmentation process, and (2) disconnect recently coalesced vesicles (i.e. vesicles separated by a partially retracted wall) so as to allow us to reconstruct the state of coalescence immediately prior to sample quench. 
The images of each stack were treated using 3DMA-Rock, which rebuilds vesicle walls in two steps. First, a 1-D representation of the vesicle network (medial axis or skeleton, Lindquist and Venkatarangan 1999) was constructed by virtual erosion, layer by layer, of the network voxels, while preserving its topological and geometrical properties (Fig. 2c). This medial axis was then cleaned by removing branches artificially computed due to image noise. Several options and parameters are available in the program while performing this step, each having a different impact on the final medial axis structure. Second, the program broke up the porosity network into individual vesicles by calculating inter-vesicle throats along the medial axis (Fig. 2d; Lindquist et al. 2000; Shin et al. 2005; Prodanovic et al. 2006). We used the "aggressive throat computation" option (Prodanovic et al. 2006), which combines three algorithms to perform this step, since our samples are highly vesiculated. Again, several options are available, and these have an impact on the number and locations of throats calculated, and hence on the calculated vesicle size distribution. Finally, 3DMA-Rock provides for each vesicle: its volume, a list of its neighbouring vesicles and the associated throats separating the vesicle from its neighbour(s).

Even by changing the multiple options and parameters used in the trimming of the medial axis and the calculation of throats, we could not totally avoid computation of some non-physical (artificial) throats (Fig. 3). However, varying the parameters changed the number and the spatial locations of these non-physical throats (Fig. 3a-c). Seven runs using different input parameters were therefore launched on one stack in order to test the impact of non-physical throats on vesicle size distribution and number density. Figure 4 shows that the impact is minor on the vesicle number distribution, since only small variations exist between the seven trials. After visual inspection of several processed stacks, we concluded that 3DMA-Rock has the tendency to forget to rebuild some walls between coalesced vesicles, rather than creating too many artificial ones. For this reason, when several trials were done on 
one stack using 3DMA-Rock, we used the one that gave the highest number of vesicles in order to build the whole size distribution.

The 3DMA-Rock program only recognizes vesicles separated by computed throats (i.e. previously connected vesicles), and naturally isolated vesicles are not identified. Processed images (including computed throats) were therefore re-analysed using ImageJ, which identifies all vesicles. The difference between the two vesicle lists then provided us with size distribution of both isolated and connected vesicles. Size distributions were then constructed for vesicles, oxide crystals and other crystalline phases, in two steps:

Step 1. Size distribution for each stack. An equivalent diameter $D$ was calculated (assuming spherical shape) for each object, and the volume and number distributions were calculated as functions of $D$ for each stack (Fig. 5a-c and Fig. 6a).

Step 2. Size distribution for the whole sample using the distributions of each stack. We first defined cut-off limits between magnifications, chosen so that: (1) each object had a diameter of at least 50 voxels, (2) each object was not larger than 0.001 of the relevant stack size, and (3) the vesicle number density distribution was the smoothest as possible. We then normalised the data at each magnification to the volume of the IPROS stack, correcting at each magnification for objects larger than the cut-off limits previously defined. This correction was applied starting at the lowest magnification (IPROS stack) and working progressively upwards. Object volume and number distributions were then obtained for the whole sample (Fig. 5d and Fig. 6b), and total vesicularity and number density were obtained by summing data from all bins. In total, 6,100-54,390 crystals and 17,820-100,480 vesicles were used to build distributions for the whole samples. This method of constructing 3D object size distributions is very similar to that used in 2D by Giachetti et al. (in press).

We also calculated the sphericity of each vesicle $\left(\Psi=\pi^{1 / 3}(6 V)^{2 / 3} / A\right.$, where $V$ is volume and $A$ is external surface area), excluding those vesicles cut by cube edges. A perfect sphere would have $\Psi=1$, whereas a highly deformed vesicle would have $\Psi \rightarrow 0$. 


\section{Results}

\section{Qualitative observations}

The following observations were made in 3D but for reasons of clarity, we often used 2D renderings of particular planes to illustrate our observations.

The three pumices are very similar and are distinct from the breadcrust bomb in their higher bulk vesicularity and thinner vesicle walls. Moreover, the three vesicle size populations recognized by Giachetti et al. (in press) in 2D are also recognized qualitatively on the 3D images, but with better resolution of textural features and spatial relationships.

Large vesicle population. The IPROS and ISTO stacks highlight the occurrence of both: (A) large angular cracks produced by phenocryst fracture (Fig. 7a) and (B) other large vesicles (Fig. 7b) that are clearly not linked to phenocrysts. Vesicles of type A are visible in all samples, but occur more commonly in breadcrust bombs ( $50 \%$ of phenocrysts $>0.5 \mathrm{~mm}$ are fractured) than in pumices $(<10 \%$ of phenocrysts $>0.5 \mathrm{~mm}$ are fractured). They occur mostly in amphiboles, but also in oxides or orthopyroxenes, and only affect phenocrysts larger than a few hundreds of microns. Four types of fracture are observed: (1) parallel to crystal length, (2) perpendicular to crystal length (Fig. 7c), (3) 1 and 2 in the same crystal (Fig. 7a), and (4) rare, more randomly oriented fractures (Fig. 7a). All four fracture types occur in the breadcrust bomb, whereas only types (1) or (2) were seen to occur in the pumices. The fractures are never filled by glass, apart from thin glass fibers connecting neighbouring crystal fragments that the high spatial resolution of the SLS images allows us to detect.

Type B vesicles are common in the pumices but very few of them are present in the breadcrust bomb (less than $\sim 5 \%$ of large vesicles). These vesicles are ragged, partly flattened vesicles that seem to be mostly aligned parallel the same direction (Fig. 7d), and seem to constitute a large fraction of the pumice vesicularity of pumice samples. 
Intermediate vesicle population. The intermediate vesicle size population (Fig. 7e) formed by coalescence of smaller vesicles, as shown by the presence of many incompletely retracted vesicle walls (Fig. 7f), as also observed by Giachetti et al. (in press), in 2D. This population does not appear clearly in the breadcrust bomb sample (Fig. 7h).

Small vesicle population. Vesicles of the small population have more spherical shapes than large or intermediate ones, and are visually mostly isolated in three dimensions. In general, the smaller the vesicle, the thicker the intervening walls (Fig. 7e-h). Small vesicles protrude into vesicles of the intermediate and large populations (Fig. $7 \mathrm{~g}$ ).

Microlites. Microlites are present in all samples, crystals of magnetite being easily visible since they stand out in white. Plagioclase microlite are qualitatively distinguishable from the glass on the SLS images even if they were not successfully distinguished in a quantitative way. The breadcrust bomb sample seems to contain more plagioclase microlites than the three pumices (Fig. 7h) as also concluded by Giachetti et al. (in press).

\section{Quantitative observations}

Glass-referenced vesicle-volume distributions are shown for the four samples in Fig. 8. Size distributions obtained using 2D image-analysis (Giachetti et al. in press) for these four samples are provided on the same figure for comparison.

The vesicle volume distribution of the breadcrust bomb is broadly bimodal, although less so than in the $2 \mathrm{D}$ data. The large population $(>160 \mu \mathrm{m}$ with a mode at $\sim 600 \mu \mathrm{m})$ is accounted for entirely by crystal-associated voids, but does not form (unlike in 2D) a distinct mode. Vesicles of the intermediate and small populations together form a single, broad peak. Almost all the vesicles are interconnected, isolated ones being smaller than a few microns and not represented on these plots. As inferred by visual inspection, the distributions of all three pumices are very similar, with a population of small vesicles with a mode at 20-30 $\mu \mathrm{m}$, a population of large vesicles $(>100-200 \mu \mathrm{m})$ and a population of intermediate vesicles with a mode at 50 to $70 \mu \mathrm{m}$, depending on the sample. The population of large vesicles has a 
minimum at 500-600 $\mu \mathrm{m}$ (see samples AMO36 and PV3) in all pumice samples. Visual inspection show that vesicles larger than $500-600 \mu \mathrm{m}$ are those linked to phenocrysts (type A) whereas those of $100-500 \mu \mathrm{m}$ are type B vesicles. Bulk vesicularities calculated by integrating the volume distributions are within 10 vol\% of those obtained by He-pycnometry (Table 1).

Despite some artefacts related to image magnification limits (e.g. cut-offs between the ISTO and IPROS data), vesicle sphericity decreases with increasing size throughout the intermediate and large populations, consistent with their more ragged shapes inherited from coalescence (Giachetti et al. in press).

Vesicle size distributions plotted using cumulative vesicle number density (Fig. 9) are significant to $\sim 2 \mu \mathrm{m}$. The cumulative number distributions of all four samples are very similar, defining approximately linear trends for vesicles $>20 \mu \mathrm{m}$. Linear trends on such plots depict power-law distributions, the slope being a fractal dimension (Gaonac'h et al. 1996a, b; Blower et al. 2001). The data from the samples give a slope of $-3.5 \pm 0.1$. Vesicles smaller than $\sim 20 \mu \mathrm{m}$, which account for more than $99 \%$ of the total vesicle number density, fall off the power-law trend, defining a different trend. Total number densities of vesicles $>2 \mu \mathrm{m}$ range from $6.6 \times 10^{14} \mathrm{~m}^{-3}$ in the breadcrust bomb to $59.1 \times 10^{14} \mathrm{~m}^{-3}$ in one of the pumices, but no systematic correlation with pyroclast vesicularity is observed.

Glass-referenced crystal volume distributions for the four pyroclasts are presented in Fig. 10. Three main populations of crystals can be recognised: phenocrysts larger than $\sim 200 \mu \mathrm{m}$ with a mode at $\sim 1-1.5 \mathrm{~mm}$, microphenocrysts with a mode around $60-100 \mu \mathrm{m}$ and microlites, smaller than few tens of $\mu \mathrm{m}$. Total crystal contents calculated vesicle-free are constant in the pumices (68 to 69 vol\%), and lower in the breadcrust bomb (36 vol\%; Table 1), consistent with the 66-90 wt\% of crystals calculated by Giachetti et al. (in press). Note that our crystal distributions include all crystal data from the IPROS and ISTO stacks, but rarely take into account plagioclase smaller than this size, due to the very low contrast from residual glass on SLS images. This has no effect on the volume distribution (except sometimes an 
artificial gap between the data from the SLS and from the ISTO stacks), but affects crystal number densities, which are not provided for this reason. It may also explain the abnormally low crystal content of the breadcrusted bomb, which is rich in plagioclase microlites, as previously shown on the SLS images (Fig. 7h). Fe-Ti oxides were easily analysed at all scales down to $2 \mu \mathrm{m}$ and their total glass-referenced number densities are 12 to $19 \times 10^{14} \mathrm{~m}^{-3}$ (Table 1). All cumulative oxide size distributions are power-law at all scales (Fig. 11). There is no correlation between oxide and vesicle number densities. Note that several microlites being $<2 \mu \mathrm{m}$, oxide number densities provided here are minima.

\section{Discussion}

Polacci et al. (2006) were among the first to use $\mu \mathrm{CT}$ in a quantitative way on scoria and pumice from explosive volcanic eruptions. They showed in particular a positive correlation between vesicle number density of the sample and eruption intensity, densities varying from $\sim 10^{9} \mathrm{~m}^{-3}$ in a Strombolian scoria (Stromboli) up to $\sim 10^{13} \mathrm{~m}^{-3}$ in a pumice from the Campanian Ignimbrite. Polacci et al. $(2008 ; 2009 a, b)$ also used $\mu$ CT to measure vesicle size distributions of scoria from Stromboli and Mt. Etna volcanoes. Their data were acquired using relatively low pixel resolutions (14 to $3.85 \mu \mathrm{m} \cdot \mathrm{px}^{-1}$ ) and connected vesicles were virtually separated using the Blob-3D program (Ketcham 2005a,b), which is useful software when working with relatively low vesicle number densities and vesicle deformations. However, this procedure does not allow us to deal with the coalescence process, since throat size distribution remains unknown. Moreover, at higher vesicle number densities like those of our samples (number densities up to $\sim 6 \times 10^{15} \mathrm{~m}^{-3}$ ), vesicle separation is much more problematic, and automated procedures are required. Degruyter et al. (2009) performed $\mu \mathrm{CT}$ on pumices from the Kos Plateau Tuff with resolutions of $\sim 6$ and $\sim 15 \mu \mathrm{m}$.px ${ }^{-1}$, and they used the 3DMA-Rock software for quantitative 3D image analysis. They measured vesicle number 
densities up to $\sim 10^{12} \mathrm{~m}^{-3}$, and used vesicle and throat size distributions to quantitatively relate Darcian permeability to the physical characteristics of the vesicle network.

In our study, the 3D vesicle and crystal size distributions were obtained by combining data from three different image stacks, with very high resolutions (up to $0.37 \mu \mathrm{m} \mathrm{px}^{-1}$ ). Although combining data from several magnifications is a common procedure in 2D imageanalysis studies (e.g. Klug et al. 1994; Shea et al. 2010; Giachetti et al. in press), to our knowledge, it has not been done before using 3D data. This approach allowed us to measure complete size distributions for vesicles as small as $2 \mu \mathrm{m}$ and as large as to $\sim 1,000 \mu \mathrm{m}$.

\section{Comparison with data from $2 D$ image analysis}

An important advantage of $\mu \mathrm{CT}$ over 2D image analysis is that it is non-destructive. For example, the problem of crystal plucking during thin sectioning is avoided. Moreover, sample preparation is trivial, since $\mu \mathrm{CT}$ requires only trimming of the sample to fit in the apparatus, sample size depending mostly on the pixel size wanted. Another advantage is that, $\mu \mathrm{CT}$ allows to work with full 3D imaging, and does not require assumptions concerning the shapes of vesicles and crystals that are indispensible when converting surface-referenced number densities to volume-referenced ones in 2D (i.e. the cut effect problem; Cheng and Lemlich 1983; Sahagian and Proussevitch 1998; Shea et al. 2010). On the other hand, $\mu$ CT produces huge amounts of data that require high computing resources.

The $\mu \mathrm{CT}$ results are now compared to those obtained on the same samples using $2 \mathrm{D}$ image analysis (Giachetti et al. in press). The two methods lead to the same qualitative observations: (1) the textural similarity of all three pumices, which differ from the breadcrust bomb, (2) the existence of distinct small and large vesicle populations in the breadcrust bomb and the existence of a third, intermediate-sized population in the pumices, and (3) the presence in pumices of large, ragged, coalesced vesicles that are essentially absent in the breadcrust bomb. Quantitative parameters obtained by the two approaches are compared in Table 1. Only objects larger than $2 \mu \mathrm{m}$ are taken into account, since this is the minimum size 
studied in $3 \mathrm{D}$. Values obtained in $2 \mathrm{D}$ were therefore recalculated using a $2 \mu \mathrm{m}$ cut-off, so as to be comparable to $3 \mathrm{D}$ values. Vesicle number densities obtained by the two methods are of the same order of magnitude, 3D values being up 3.5 times lower to 2.3 times higher than the $2 \mathrm{D}$ values. In both cases the cumulative number density distributions exhibit power-law trends (attributed to coalescence) for vesicles $>20 \mu \mathrm{m}$ and an exponential trend for those $<20$ $\mu \mathrm{m}$. Fe-Ti oxide number densities obtained by 3D-analysis are 1.1 to 3.3 times lower than those obtained in 2D. The cumulative number density distribution of oxides obtained in 3D follows a power-law distribution at all scales, as in $2 \mathrm{D}$. These good qualitative and quantitative agreements between the two techniques suggest that our 3D approach has captured the vesicle and crystal size distributions correctly, at least to a first approximation. There is also good agreement between the 3D total vesicularities and those provided by $\mathrm{He}$ pycnometry (see Table 1).

There are, however, some artefacts in the tomography data. First, the 3DMA-Rock program seems to be unable to dismantle a part of the vesicle network on ISTO images, even using the aggressive throat computation option. This has the effect of artificially increasing the amount of intermediate vesicles, explaining why the breadcrust bomb shows a population of intermediate vesicles that does not exists in the $2 \mathrm{D}$ vesicle volume distributions. The correction for the presence in some of the ISTO and SLS images of these very large, unrealistic, vesicles not successfully de-coalesced by 3DMA-Rock, artificially increases some peaks in the vesicle volume distributions, in particular those of the intermediate population (Fig. 8). Consequently, it slightly increases the total vesicularities of some samples (BCP1c, AMO36) compared to He-pycnometry values (Table 1). However, visual inspection of the raw images (e.g., Fig. 7e) and resulting histograms for each stack show that the different vesicle populations mentioned before are real. Moreover, we do not think that this artefact has a large effect on vesicle number distributions as shown by the good concordance between $2 \mathrm{D}$ and 3D cumulative number distributions (Fig. 9). Even with the very high resolution of the 
SLS images, isolated vesicles are very rare, due to the presence of some wrongly segmented pixels that artificially connect many isolated vesicles to their neighbours. For this reason, the isolated vesicle population, known to exist from He pycnometry measurements (from $\sim 5$ to $\sim 11 \mathrm{vol} \%$ in these four samples; Giachetti et al. in press), is almost missing in the 3D results. Finally, the crystal size distributions are significant only for crystals larger than few tens of microns due to the impossibility of quantitatively distinguishing plagioclase from glass on SLS images. This problem could certainly be corrected by changing the image acquisition setup and in particular the beam intensity. On the other hand, the Fe-Ti oxide size distributions are valid down to $2 \mu \mathrm{m}$.

\section{Origins of the vesicle populations}

Since our four samples are the same as in Giachetti et al. (in press), and since qualitative and quantitative observations are similar in $2 \mathrm{D}$ and $3 \mathrm{D}$, our interpretations of vesicle population origins are the same. These interpretations are summarized briefly. Small vesicles that are present in all pyroclasts are interpreted as having nucleated heterogeneously and grown syn-explosively (Giachetti et al. in press). In particular, they are present in the breadcrust bomb which formed by syn-explosive inflation of initially non-vesicular magma. Intermediate-population vesicles present in pumices are also syn-explosive in origin, because they formed by the coalescence of the small syn-explosive vesicles (Fig. 7f). Vesicles of the large population have a mixed origin. The large angular voids formed by phenocryst fracture are syn-explosive, whereas the large ragged, channel-like vesicles that are commonly present in the pumices, but absent in the breadcrust bombs, are interpreted as being probably preexplosive, i.e., they existed in the conduit prior to each explosion. The common elongated form of these large vesicles (Fig. 7d, g) can be attributed to (1) stretching by viscous flow of bubbly magma in the periods between explosions or, (2) degassing-induced vesicle collapse quenched in progress by the explosion. 


\section{Mechanisms of syn-explosive vesiculation}

\section{Bubble nucleation}

The data confirm the conclusion of Giachetti et al. (in press) that syn-explosive nucleation of vesicles took place heterogeneously. Oxide cumulative number density follows a power-law distribution at all scales (Fig. 11). Tomography-derived oxide number densities down to $2 \mu \mathrm{m}$ are of the same order of magnitude than those of vesicles, showing that sufficient nucleation sites were available (Table 1). Moreover, there is visual evidence of wetting of oxide crystals by gas, which is consistent with bubble heterogeneous nucleation on titanomagnetite while it is not the case for other mineral phases (Fig. 12).

We used the decompression rate meter of Toramaru (2006), the water diffusivities provided by Giachetti et al. (in press), a temperature of $850^{\circ} \mathrm{C}$ (Devine et al. 2003), and a surface tension of $0.025 \mathrm{~N} \mathrm{~m}^{-1}$ (Cluzel et al. 2008), (Table 1), the interstitial glass water contents and saturation pressures estimations of Burgisser et al. (submitted) and our total vesicle number densities (that equal those of the small plus intermediate populations) to calculate syn-explosive decompression rates. The values obtained for the four samples range from 0.4-1.3 MPa.s ${ }^{-1}$ for the breadcrust bomb to $0.3-5.1 \mathrm{MPa}^{-1}{ }^{-1}$ for the pumices. These estimates are consistent with those based on the $2 \mathrm{D}$ vesicle number densities (0.3 to 6.5 MPa.s ${ }^{-1}$; Giachetti et al. in press).

\section{Bubble coalescence}

Computed microtomography provides a unique chance to quantitatively investigate the coalescence process, that could not be studied directly using a $2 \mathrm{D}$ approach. The microtomography images confirm the importance of coalescence in the vesiculation of the Vulcanian pyroclasts deduced by Giachetti et al. (in press). Moreover, 3DMA-Rock provides a list of the walls built in the decoalescence process, and this allows us to construct vesicle throat size distributions using the same approach as used for vesicle size distributions. Cumulative throats number distributions (Fig. 13) follow broadly power-law distributions for 
sizes larger than a few microns, some artefacts related to stack limits occurring at $\sim 30 \mu \mathrm{m}$ and $\sim 200 \mu \mathrm{m}$. Below a few microns, the distributions seem to follow exponential trends, like the vesicle size distributions (Fig. 9). Total throat number densities range from 3.4 to $133 \times 10^{14} \mathrm{~m}^{-}$ ${ }^{3}$, with no correlation with vesicle number density. They do, however, correlate with pyroclast vesicularity, being lowest in the breadcrust bomb $\left(3.4 \times 10^{14} \mathrm{~m}^{-3}\right)$, intermediate in the dense pumices $\left(13-22 \times 10^{14} \mathrm{~m}^{-3}\right)$ and highest in the most vesicular pumice $\left(133 \times 10^{14} \mathrm{~m}^{-3}\right)$. Mean throat diameter ranges from 5.6 to $6.8 \mu \mathrm{m}$. Since throat size distribution and vesicularity both influence permeability (Saar and Manga 1999, Blower 2001; Mueller et al. 2005; Costa 2006; Bernard et al. 2007), we deduce that permeability increases from the breadcrust bomb to the most vesicular pumice (Table 1).

The output files provided by 3DMA-Rock also allow us to determine if there is a relationship between the number of connections per vesicle and its size, and also if coalescence preferentially occurs between vesicles of similar size or not. Since a vesicle could be connected $\mathrm{X}$ times to a particular neighbour by $\mathrm{X}$ different throats, we analysed both the number of connections and the number of neighbours for each vesicle (the latter value being equal to, or smaller than, the former). Figure 14 shows the relationship between vesicle size and the average number of connections (a) or neighbours (b). The three sets of curves on each plot correspond to the three image stacks, the number of connections or neighbours of a single vesicle decreasing in the order SLS-ISTO-IPROS due to the progressive decrease in resolution. As intuitively expected, both the number of connections and the number of neighbours increase with vesicle size, but no systematic variation with pyroclast type is observed.

The range of sizes over which coalescence occurs is shown in Fig. 15. Each point represents a pair of coalesced vesicles, and for this reason they are symmetrical about a line 1:1 and are represented only on one part. The plots show that coalescence occurs between vesicles of all different sizes, suggesting that, during growth, a vesicle will coalesce with its 
neighbours irrespective of their size, coalescence affecting indifferently pre- and synexplosive bubbles. However, the weak higher concentration of points in a disc in the middle of the data of each stack seems to imply that vesicles preferentially coalesce with neighbour of similar size.

Figure 14 shows that in the breadcrust bomb, the number of connections and neighbours are broadly the same, whereas in the pumices, vesicles have much more connections than neighbours. This is also visible in Fig. 15 where the number of points in the graph is higher for the breadcrust bomb sample than for the pumices. This means that in the pumices two neighbouring vesicles are connected by several throats (resulting in a single point on the Fig. 15), whereas in the breadcrust bomb, vesicles are connected fewer times with the same vesicle. There are two possible explanations for this observation: (1) vesicles in the pumices are much more deformed than in the breadcrust bomb and thus have more chance to be connected several times or (2) vesicles walls are thinner in the pumices than in the breadcrust bomb. Process (1) is not favoured by the vesicle sphericity distribution that seems to be identical for breadcrust bomb and pumices (Fig. 9). Moreover, the second explanation is supported by direct visual observation (compare Fig. 7e-g with Fig. 7h). This observation is linked to the fact that bubble growth in the pumices is better developed than in the breadcrust bomb, resulting in thinner vesicle walls, facilitating the occurrence of coalescence process in the pumices between two vesicles. Thus, $\mu \mathrm{CT}$ also gives indirectly useful information about the mean thicknesses of vesicle walls.

\section{Conclusion}

X-Ray computed microtomography was carried out on four pyroclasts from the 1997 Vulcanian explosions of Soufrière Hills Volcano, Montserrat. For the first time, 3D data from multiple image stacks with different spatial resolutions (including a very high spatial resolution of $0.37 \mu \mathrm{m} \cdot \mathrm{px}^{-1}$ ) were combined to construct vesicle and crystal size distributions 
from $2 \mu \mathrm{m}$ up to $1 \mathrm{~mm}$ in diameter. High vesicle number densities (up to $\sim 60 \times 10^{14} \mathrm{~m}^{-3}$ ) associated with very thin vesicle walls $(\sim 1 \mu \mathrm{m})$ rendered quantitative data hard to obtain and required automated decoalescing of the vesicle network. However, these results showed good qualitative and quantitative agreements with those obtained on the same samples using $2 \mathrm{D}$ image-analysis. Bulk vesicularities also show good agreement with those obtained by Hepycnometry. Further improvements in the decoalescence process is needed in order to avoid problems linked to the presence of large, unrealistic, vesicles that were not successfully decoalesced by 3DMA-Rock, and that result in some artefacts in the size distributions.

The use of the 3DMA-Rock program to perform decoalescence of the vesicle network provided a unique chance to investigate the natural coalescence process in 3D. Coalescence in all pyroclasts occurred between neighbouring bubbles of any sizes, but, as intuitively expected, the larger the vesicle, the more connected it is. Coalescence thus affected indifferently pre- and syn-explosive bubbles, suggesting that the syn-explosive gas was rapidly connected to large-scale pathways through which it could escape. This process was largely facilitated in the pumices due to the small thickness of vesicle walls.

\section{Acknowledgments}

This project was partly funded by the French Agence Nationale de la Recherche (ANR-EXPLANT, Contract No ANR-05-CATT-003 to C. Martel). The study benefited from discussions with Jonathan Castro, Wim Degruyter, Emmanuel Le Trong. Marco Stampanoni, Emmanuel Le Trong and David Picard helped us at the Swiss Light Source and Armelle Basillais acquired the IPROS stacks at the Institut de Prévention et de Recherche sur l'Ostéoporose (IPROS), Orléans. 


\section{References}

Adams NK, Houghton BF, Hildreth W, (2006) Abrupt transitions during sustained explosive eruptions: examples from the 1912 eruption of Novarupta, Alaska. Bull. Volcanol. 69, $189-206$

Bernard ML, Zamora M, Geraud Y, Boudon G (2007) Transport properties of pyroclastic rocks from Montagne Pelee volcano (Martinique, Lesser Antilles). Journal of Geophysical Research-Solid Earth 112(B5)

Blower JD, Keating JP, Mader HM, Phillips JC (2001) Inferring degassing processes from vesicle size distributions. Geophys. Res. Lett. 28, 347-350

Bouvet de Maisonneuve C, Bachmann O, Burgisser A (2008) Characterization of juvenile pyroclasts frmo the Kos Plateau Tuf (Aegean Arc): insights into the eruptive dynamics of a rhyolitic caldera-forming eruption. Bull Volcanol. Doi: 10.107/s004455-0080250-x

Cheng HC, Lemlich R (1983) Errors in the measurement of bubble-size distribution in foam. Industrial and Engineering Chemistry Fundamentals 22, 105-109

Clarke AB, Neri A, Voight B, Macedonio G, Druitt TH (2002). Computational modelling of the transient dynamics of the August 1997 vulcanian explosions at Soufrière Hills Volcano, Montserrat; influence of initial conduit conditions on near-vent pyroclastic dispersal. In: Druitt, T.H., Kokelaar, B.P. (ed) The eruption of Soufrière Hills Volcano, Montserrat, from 1995 to 1999 . Geological Society of London Memoir, vol. 21, 319-348

Clarke AB, Stephens S, Teasdale R, Sparks RSJ, Diller K (2007) Petrologic constraints on the decompression history of magma prior to Vulcanian explosions at the Soufrière Hills volcano, Montserrat. J. Volcanol. Geotherm. Res. 161, 261-274 
Cluzel N, Laporte D, Provost A, Kannewischer I (2008) Kinetics of heterogeneous bubble nucleation in rhyolitic melts: implications for the number density of bubbles in volcanic conduits and for pumice textures. Contrib. Mineral. Petrol. 156, 745-763

Costa A (2006) Permeability-porosity relationship: A reexamination of the Kozeny-Carman equation based on a fractal pore-space geometry assumption. Geophysical Research Letters 33(2):- Eichleberger JC, Carrigan CR, Westrich HR, Price RH (1986) Nonexplosive silicic volcanism. Nature 323:598-602

Degruyter W, Bachmann O, Burgisser A (2009) Controls on magma permeability in the volcanic conduit during the climactic phase of the Kos Plateau Tuff eruption (Aegean Arc). Bull Volcanol DOI 10.1007/s00445-009-0302-X

Devine JD, Rutherford MJ, Norton GE, Young, SR, (2003) Magma storage region processes inferred from geochemistry of Fe-Ti oxides in andesitic magma, Soufriere Hills Volcano, Montserrat, WI. Journal of Petrology 44, 1375-1400

Diller K, Clarke AB, Voight B, Neri A (2006) Mechanisms of conduit plug formation: implications for vulcanian explosions. Geophys. Res. Lett. 33:L20302

Druitt TH, Young SR, Baptie BJ, Bonadonna C, Calder ES, Clarke A, Cole PD, Harford CL, Herd RA, Lockett R, Ryan G, Voight B (2002) Episodes of cyclic vulcanian explosive activity with fountain collapse at Soufrière Hills Volcano, Montserrat. In: Druitt TH, Kokelaar BP (Eds.), The eruption of Soufrière Hills Volcano, Montserrat, from 1995 to 1999. Geological Society of London Memoir (21):281-306

Eichelberger JC, Carrigan CR, Westrich HR, Price RH (1986) Non-explosive silicic volcanism. Nature. 323, 598-602

Formenti Y, Druitt TH, Kelfoun K (2003) Characterisation of the 1997 Vulcanian explosions of Soufrière Hills Volcano, Montserrat, by video analysis. Bull Volcanol 65:587-605

Gaonac'h H, Lovejoy S, Stix J, Schertzer D (1996a) A scaling growth model for bubbles in basaltic flows. Earth Planet. Sci. Lett. 139:395-409 
Gaonac'h H, Stix J, Lovejoy S (1996b) Scaling effects on vesicles shape, size and heterogeneity of lavas from Mount Etna. J. Volcanol. Geotherm. Res. 74:131-153

Gardner JE (2007) Heterogeneous bubble nucleation in highly viscous silicate melts during instantaneous decompression from high pressure. Chem. Geol. (236): 1-12

Gonnerman HM, Manga M (2007) The fluid mechanics inside a volcano. Annu Rev Fluid Mech 39:321-356. doi: 10.1146/annurev.fluid.39.050905.110207

Kennedy B, Spieler O, Scheu B, Kueppers U, Taddeucci J, Dingwell DB (2005) Conduit implosion during Vulcanian eruptions. Geology 33, 581-584

Ketcham RA (2005a) Computational methods for quantitative analysis of three-dimensional features in geological specimens. Geosphere 1(32-41)

Ketcham RA (2005b) Three-dimensional grain fabric measurements using high-resolution Xray computed tomography. Journal of Structural Geology 27(7):1217-1228

Klug C, Cashman KV (1994) Vesiculation of May 18, 1980, Mount St. Helens magma. Geology. 22:468-472

Klug C, Cashman KV (1996) Permeability development in vesiculating magmas: implications for fragmentation. Bull. Volcanol. 58:87-100

Klug C, Cashman KV, Bacon CR (2002) Structure and physical characteristics of pumice from the climatic eruption of Mount Mazama (Crater Lake), Oregon. Bull. Volcanol. $64: 486-501$

Lindquist WB (1999) 3DMA general users manual. SUNY-Stony Brook technical report SUNYSB-AMS-99-20

Lindquist WB, Venkatarangan A (1999) Investigating 3D geometry of porous media from high resolution images. Physics and Chemistry of the Earth Part a-Solid Earth and Geodesy 24(7):593-599 
Lindquist WB, Venkatarangan A, Dunsmuir J, Wong TF (2000). Pore and throat size distributions measured from synchrotron X-ray tomographic images of Fontainebleau sandstones. Journal of Geophysical Research-Solid Earth 105(B9):21509-21527

Mason RM, Starostin AB, Melnik OE, Sparks RSJ (2006) From Vulcanian explosions to sustained explosive eruptions: the role of diffusive mass transfer in conduit flow dynamics. J. Volcanol. Geotherm. Res. 153:148-165

Melnik O, Sparks RSJ (2002) Modelling of conduit flow dynamics during explosive activity at Soufrière Hills Volcano, Montserrat. In: Druitt TH, Kokelaar BP (ed) The eruption of Soufrière Hills Volcano, Montserrat, from 1995 to 1999. Geological Society of London Memoir, vol. 21, 307-317

Mueller S, Melnik O, Spieler O, Scheu B, Dingwell DB (2005) Permeability and degassing of dome lavas undergoing rapid decompression: An experimental determination. Bulletin of Volcanology 67(6):526-538

Namiki A, Manga M (2008) Transition between fragmentation and permeable outgassing of low viscosity magmas. J Volcanol Geotherm Res 169(1-2):48-60. doi:101016/j.jvolgeores.2007.07.020

Polacci M, Baker DR, Mancini L, Tromba G, Zanini F (2006) Three-dimensional investigation of volcanic textures by X-ray microtomography and implications for conduit processes. Geophysical Research Letters 33(13):L13312. doi: 10.1029/2006GL026241

Polacci M, Baker DR, Liping B, Mancini L (2008) Large vesicles record pathways of degassing at basaltic volcanoes Bull Volcanol 70:1023-1029

Polacci M, Burton MR, La Spina A, Murè F, Favretto S, Zanini F (2009a) The role of syneruptive vésiculation on explosive basaltic activity at Mt. Etna, Italy. J. Volcanol. Geotherm. Res. 179, 265-269 
Polacci M, Baker DR, Mancini L, Favretto S, Hill RJ (2009b) Vesiculation in magmas from Stromboli and implications for normal Strombolian activity and paroxysmal explosions in basaltic systems. J. of Geophys. Res. 114, B01206

Prodanovic M, Lindquist WB, Seright RS (2006) Porous structure and fluid partitioning in polyethylene cores from 3D X-ray microtomographic imaging. Journal of Colloid and Interface Science 298(1):282-297

Prodanovic M, Lindquist WB, Seright RS (2007) 3D image-based characterization of fluid displacement in a Berea core. Advances in Water Resources 30(2):214-226

Saar MO, Manga M (1999) permeability-porosity relationship in vesicular baslts. Geophysical Research Letters 26(1):111-114

Sahagian DL, Proussevitch AA (1998) 3D particle size distributions from 2D observations: stereology for natural applications. J. Volcanol. Geotherm. Res. 84:173-196

Shea T, Houghton BF, Gurioli L, Cashman KV, Hammer JE, Hobden BJ (2010) Textural studies of vesicles in volcanic rocks: An integrated methodology. J. Volcanol. Geotherm. Res. 190, 271-289

Shin H, Lindquist WB, Sahagian DL, Song S-R (2005) Analysis of the vesicular structure of basalts. Comput Geosci 31(4):473-487.doi:10.1016/j.cageo.2004.10.013

Song SR, Jones KW, Lindquist WB, Dowd BA, Sahagian DL (2001) Synchrotron X-ray computed microtomography: studies on vesiculated basaltic rocks. Bull Volcanol. 63(4):252-263. doi: 10.1007/s004450100141

Spieler O, Dingwell DB, Alidibirov M (2004a) Magma fragmentation speed: an experimental determination. J. Volcanol. Geotherm. Res. 129:109-123

Spieler O, Kennedy B, Kueppers U, Dingwell DB, Scheu B, Taddeucci J (2004b) The fragmentation threshold of pyroclastic rocks. Earth Planet. Sci. Lett. 226(1-2):139-148

Toramaru A (2006) BND (bubble number density) decompression rate meter for explosive volcanic eruptions. J. Volcanol. Geotherm. Res. 154:303-316 


\section{Figure Captions}

Fig. 1: Planes arbitrarily chosen from the three image stacks. a IPROS, b ISTO and c SLS. The image resolutions are $\sim 17.4, \sim 4.0$ and $0.37 \mu \mathrm{m} . \mathrm{px}^{-1}$ respectively. The sample imaged here is the breadcrust bomb interior BCP1c. Vesicles appear black, glass, plagioclase, hornblende and pyroxene grey, and Fe-Ti oxides white.

Fig. 2: Three-dimensional rendering of the SLS stacks of the pumice PV3. a Raw, grey-scale images. Vesicles appear in dark grey, glass, plagioclase, hornblende and pyroxene in pale grey, and Fe-Ti oxides in white. b After segmentation of vesicles. Crystals and glass are shown in brown, and vesicles are not highlighted. c After 3DMA-Rock calculation of the medial axis that appears as blue points. d After building of vesicle throats that appear in purple.

Fig. 3: Examples of non-physical throats computed by 3DMA-Rock. Vesicles are shown in white, crystals and glass are in black and the computed vesicle throats are in grey. The five black arrows are at the same place on all the images and show the displacement of computed throats, depending on the input parameters in 3DMA-Rock for the medial axis trimming and throats computation steps (see text for explanation).

Fig. 4: Vesicle size distributions obtained for one stack of images using seven sets of input parameters in 3DMA-Rock. This graph shows the minor impact of non-physical throats on the vesicle number distribution, both in terms of total number density and in terms of the form of the distribution.

Fig. 5: Relative vesicle volume distributions obtained for each single image stack of breadcrust bomb BCP1c, and vesicle volume distribution calculated for the whole sample. 
Fig. 6: a Vesicle number distributions obtained for each image stack for breadcrust bomb BCP1c showing the large overlaps that exist between data from the three stacks. The cut-off limits defined in the text are shown by dashed lines. b Number distribution calculated for the whole sample. Visual inspection shows that only minor artefacts are created by stack combination.

Fig. 7: Two- and three-dimensional renderings of particular planes or objects in each stack of images. a Large fractured phenocrysts in breadcrust bomb BCP1c. b Large, ragged, channellike vesicles in dense pumice AMO36 set into small and intermediate vesicles. c 3D rendering of an amphibole fractured perpendicular to its length (pumice PV3), showing the angular characteristics of the voids formed by this process. d Large, elongated bubbles (B), and angular void (A) created by phenocryst fracture in PV3. e Intermediate-sized vesicle in dense pumice AMO36. f Evidence for coalescence quenched in progress in dense pumice AMO29, shown by the presence of incompletely retracted vesicle walls (black arrows). g Extremity of a large, elongated vesicle and its relationships to small and intermediate-sized vesicles. The smaller vesicles penetrate into the large vesicle (black arrows). $\mathbf{h}$ Texture of the breadcrust bomb interior (BCP1c) on the SLS images. Vesicle walls are thicker and many plagioclase microlites (black arrows) can be distinguished from the residual glass.

Fig. 8: Glass-referenced vesicle volume (dark grey) and sphericity distributions as functions of vesicle size. In light grey in the background and with a thin black line are also represented the vesicle volume distributions obtained by Giachetti et al. (in press) using 2D imageanalysis. The limits between the different stacks are marked by vertical dashed lines and visual inspection show only minor artefacts around $30-40 \mu \mathrm{m}$. These artefacts are due to the correction applied for the presence on most of the ISTO and SLS stacks of a package of 
vesicles that was not successfully dismantled by the 3DMA-Rock program, forming one unrealistic, artificial, vesicle.

Fig. 9: Glass-referenced cumulative vesicle number densities for the four pyroclasts analysed. A best-fit power law for vesicles larger than $20 \mu \mathrm{m}$ is also shown as well as the field (grey) covered by the cumulative vesicle number densities obtained by Giachetti et al. (in press) for the same sample (cut at $\sim 2 \mu \mathrm{m}$ to be directly compared with our data).

Fig. 10: Glass-referenced crystal volume distributions. The vertical dashed lines are the image-stack magnification limits.

Fig. 11: Glass-referenced cumulative oxide number densities for the four pyroclasts analysed. This graph show that oxides distribution are power-law at all scales.

Fig. 12: Textural evidence for heterogeneous nucleation of bubbles on titanomagnetite crystals. Contrary to other mineral phases, Fe-Ti oxides are not wetted by glass.

Fig. 13: Throat size distributions for the four pyroclasts.

Fig. 14: a Relationships between the size of a vesicle and its number of connections with neighbouring vesicles. b Relationships between the size of a vesicle and its number of neighbours.

Fig. 15: Equivalent diameters of the two vesicles of each couple of coalesced vesicles. These graphs are symmetrical by a line $1: 1$, by definition. 


\section{igures}

Figure 1
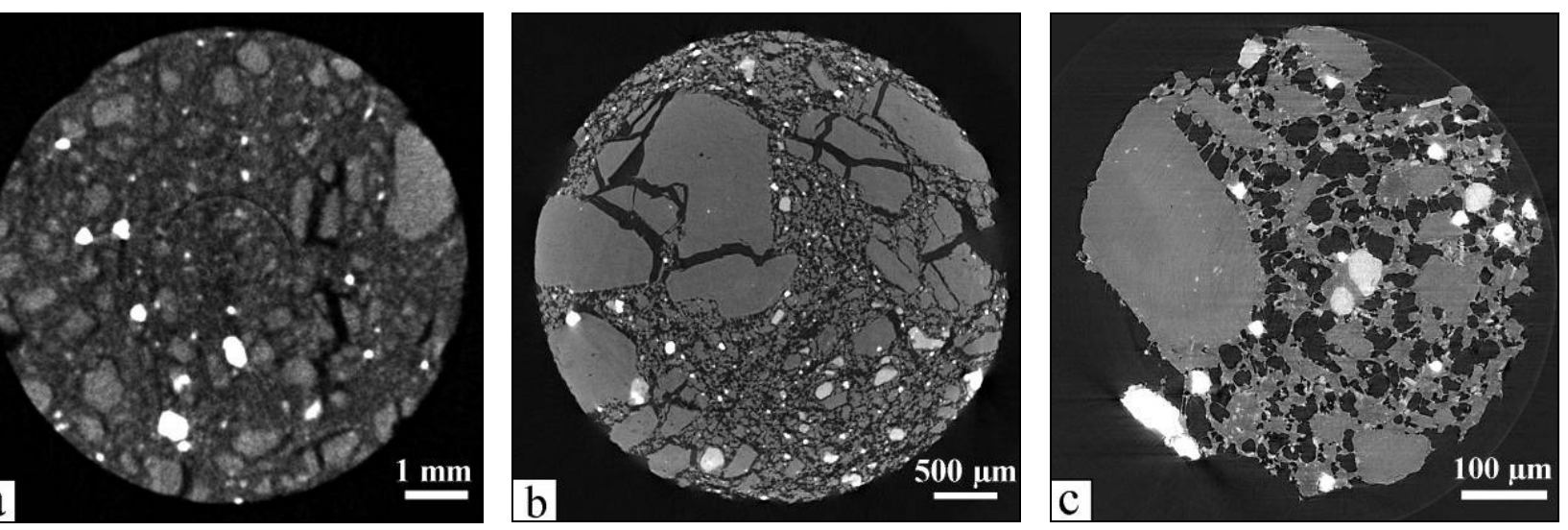

Figure 2

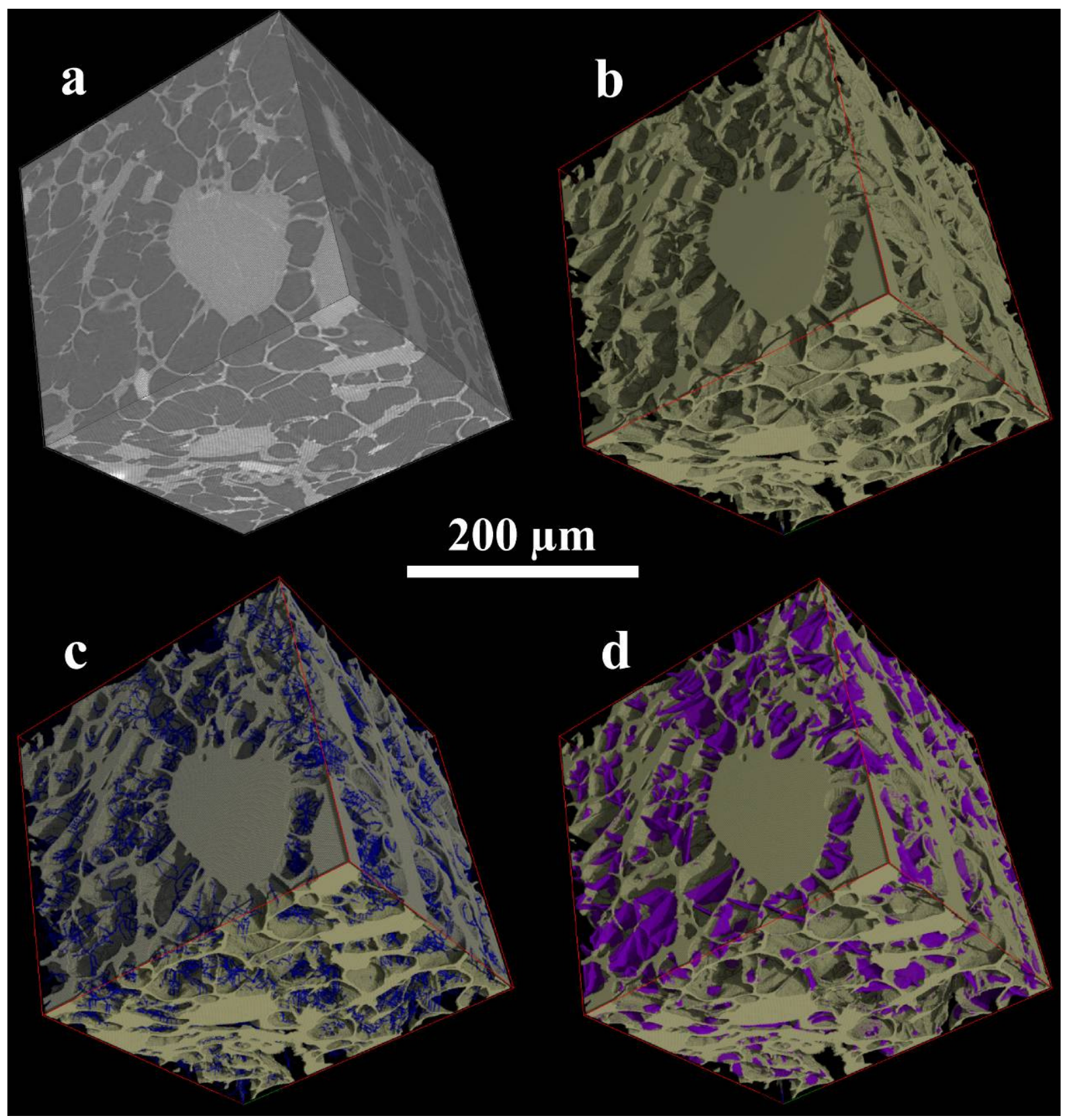


Figure 5
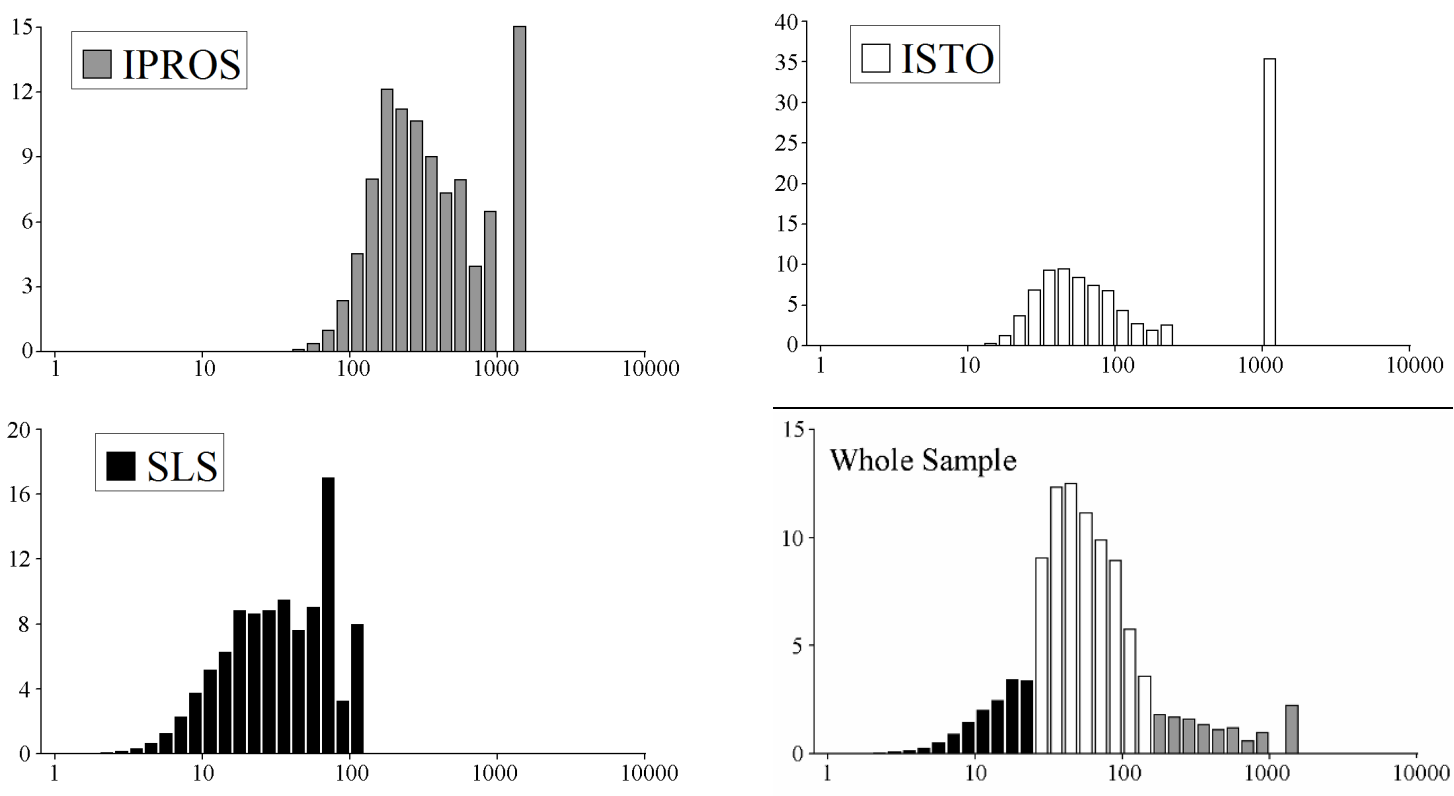

Vesicle Equivalent Diameter $(\mu \mathrm{m})$

Figure 6

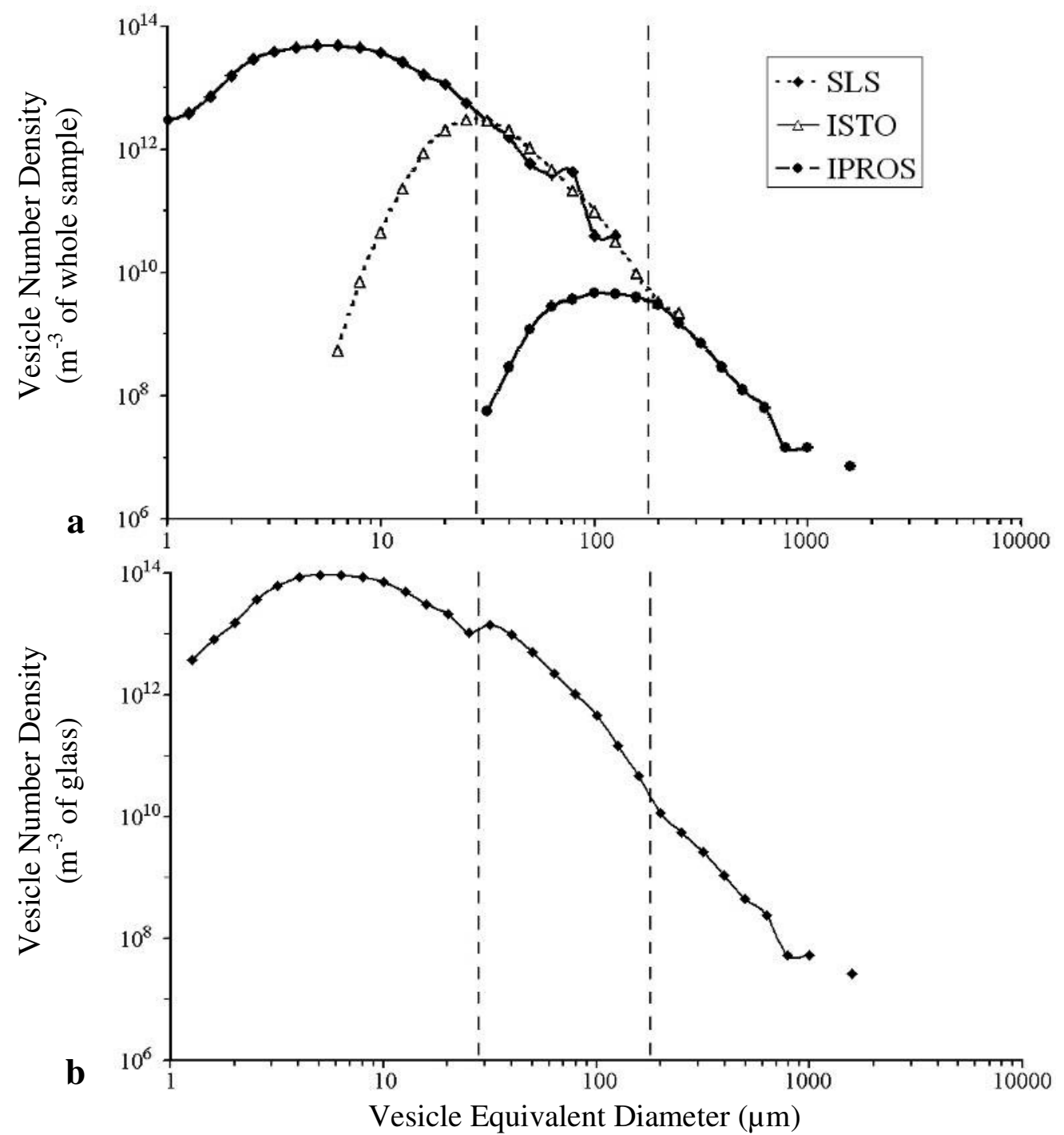


Figure 7
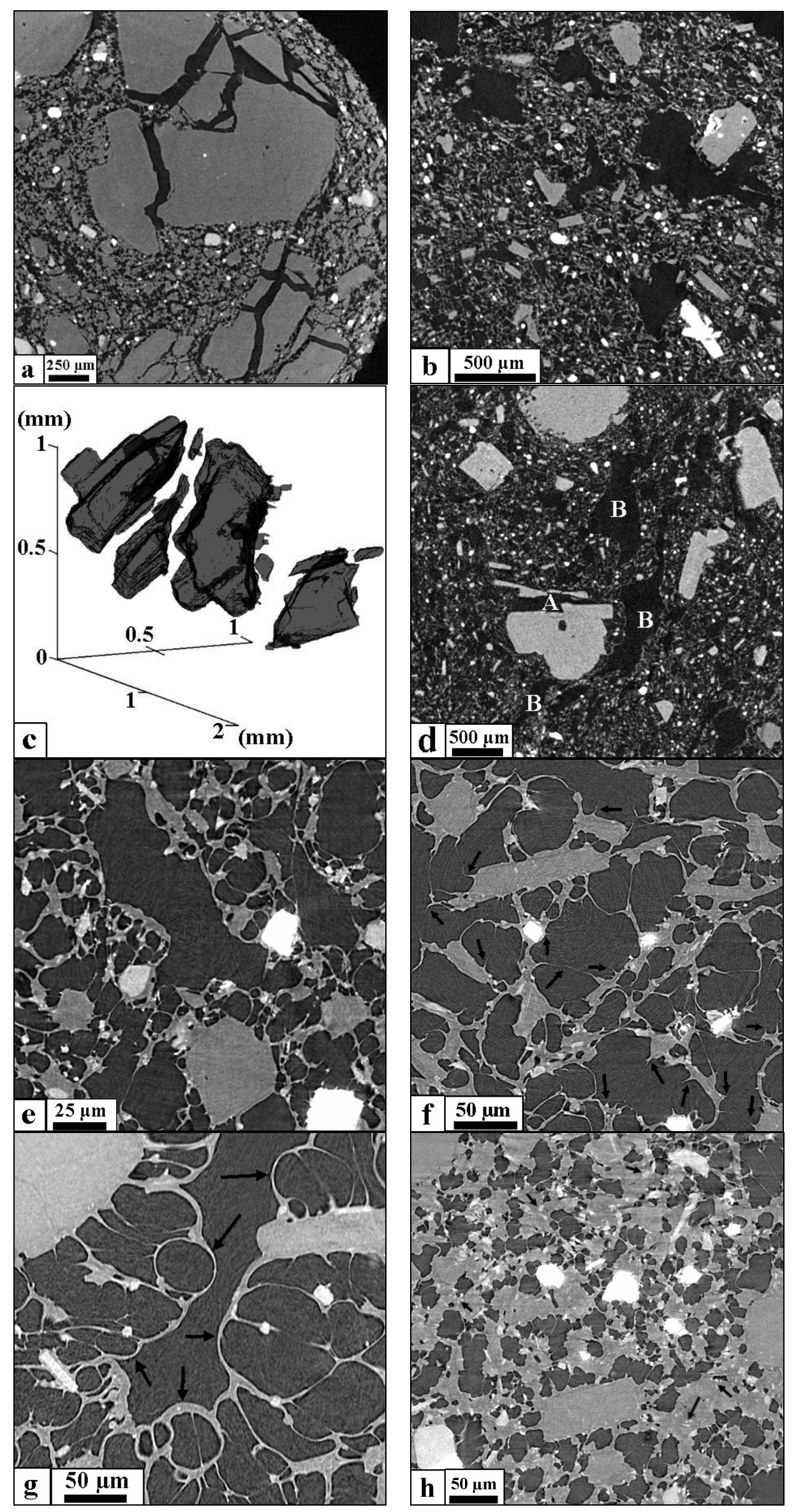


\section{Figure 8}

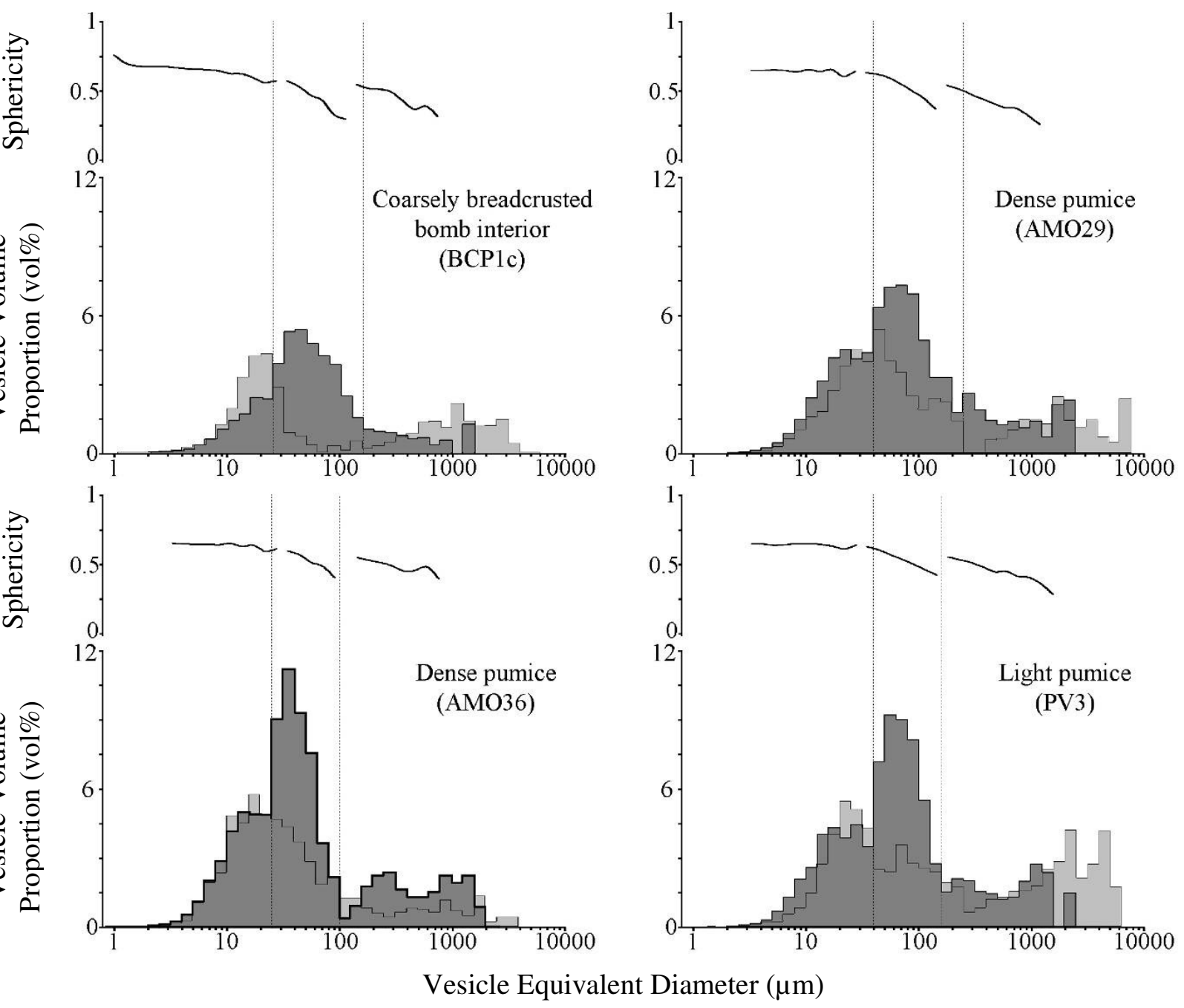

Figure 9

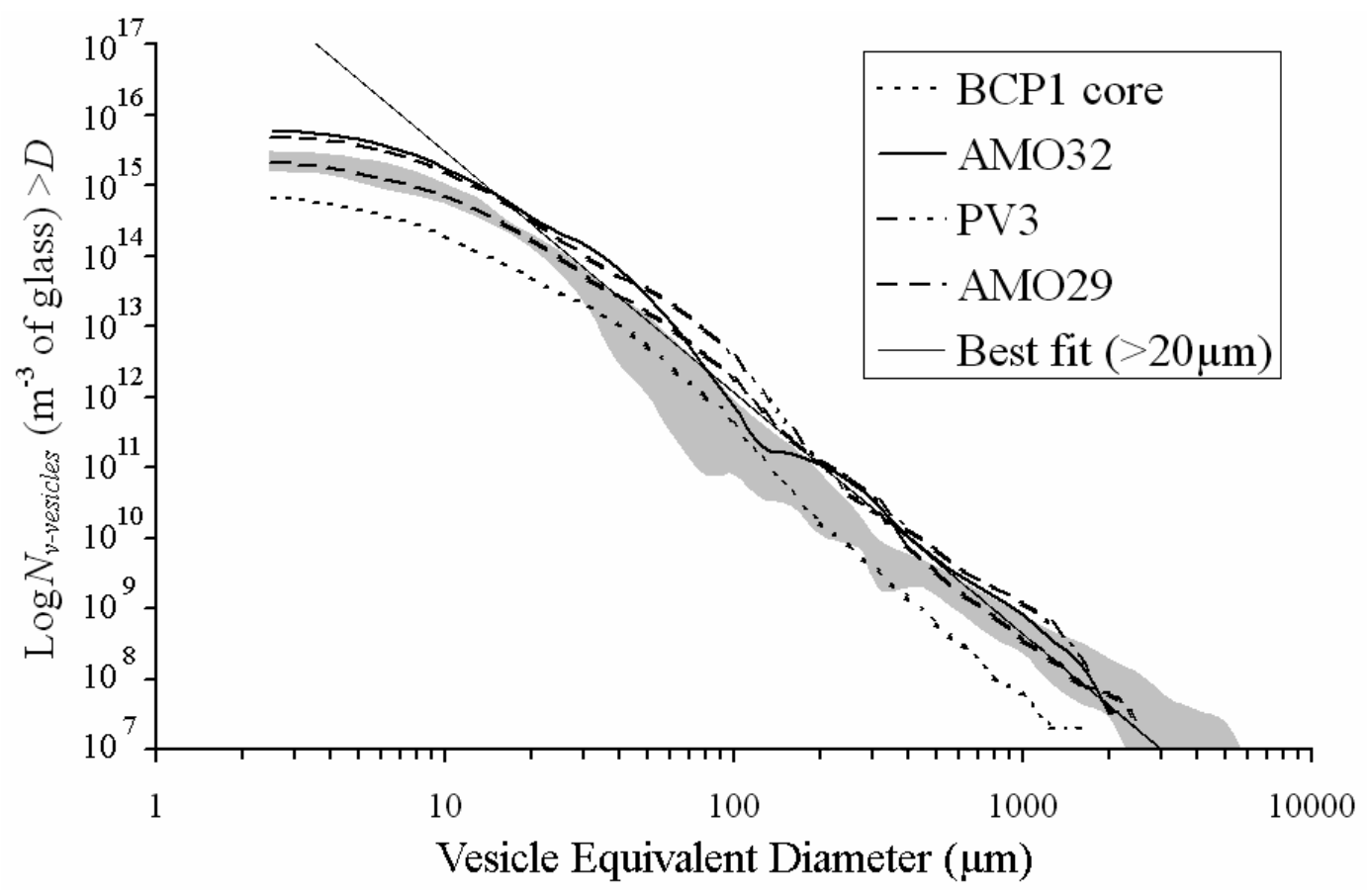


Figure 10
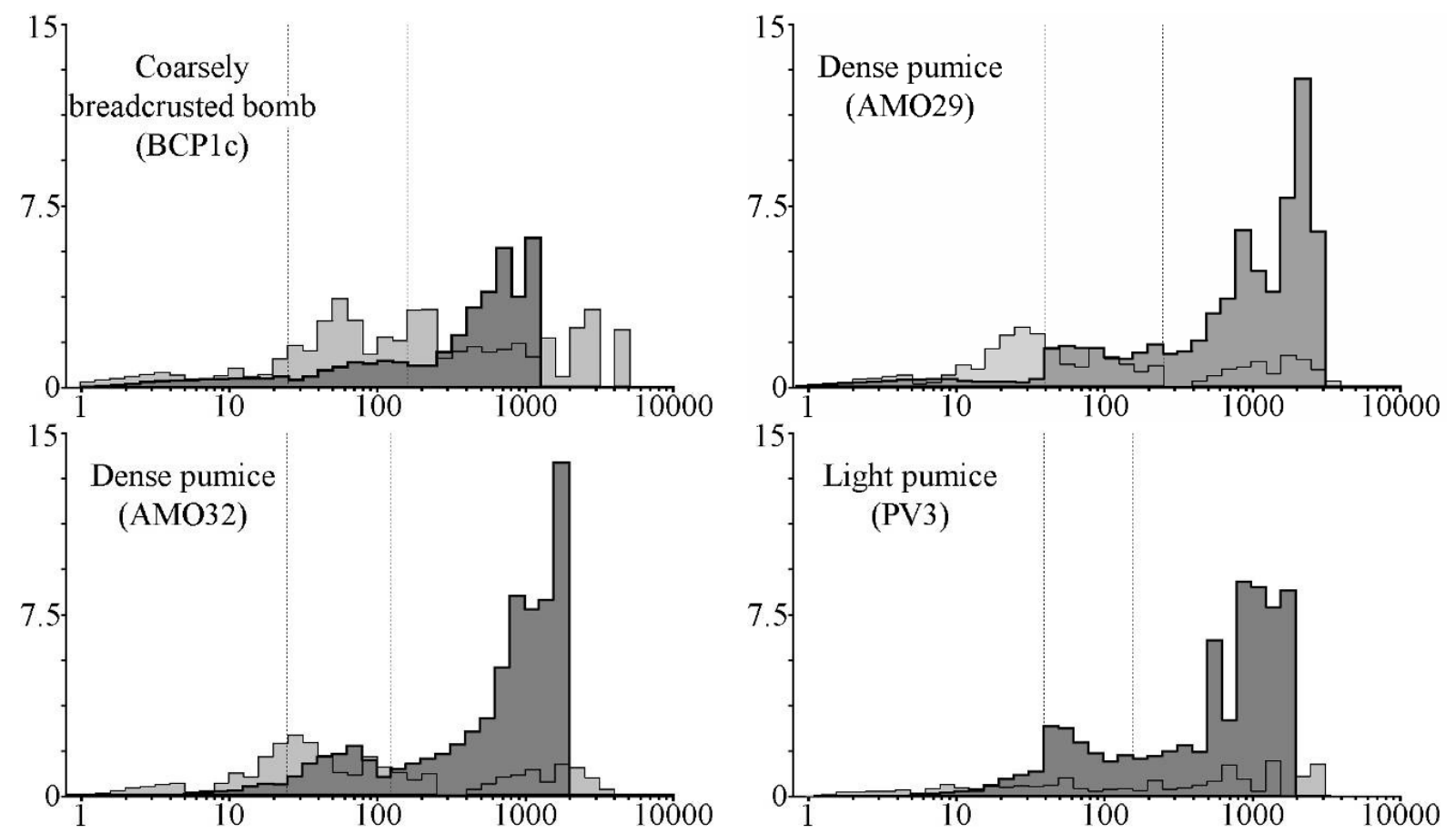

Crystal Equivalent Diameter $(\mu \mathrm{m})$

Figure 11

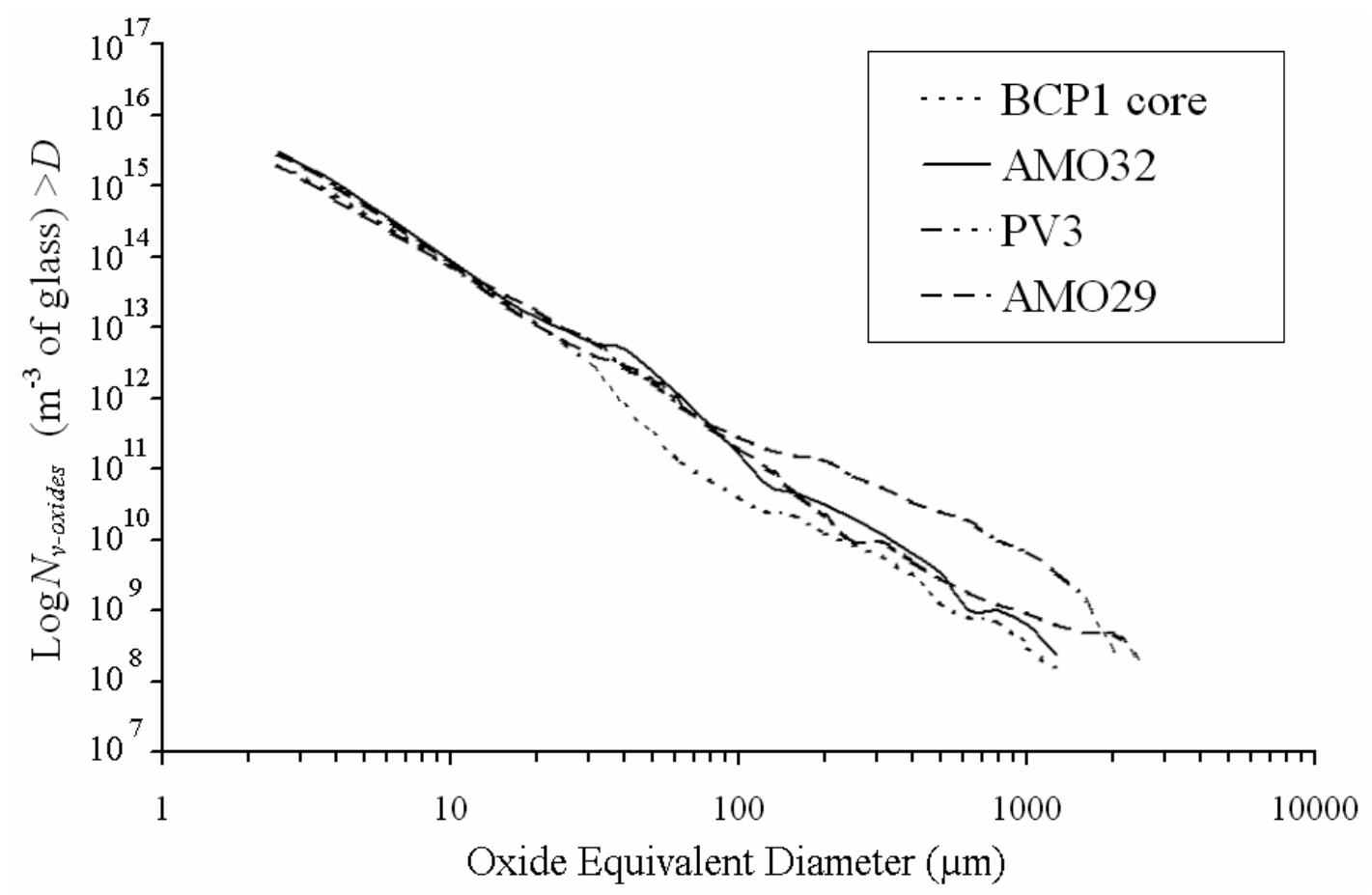


Figure 12

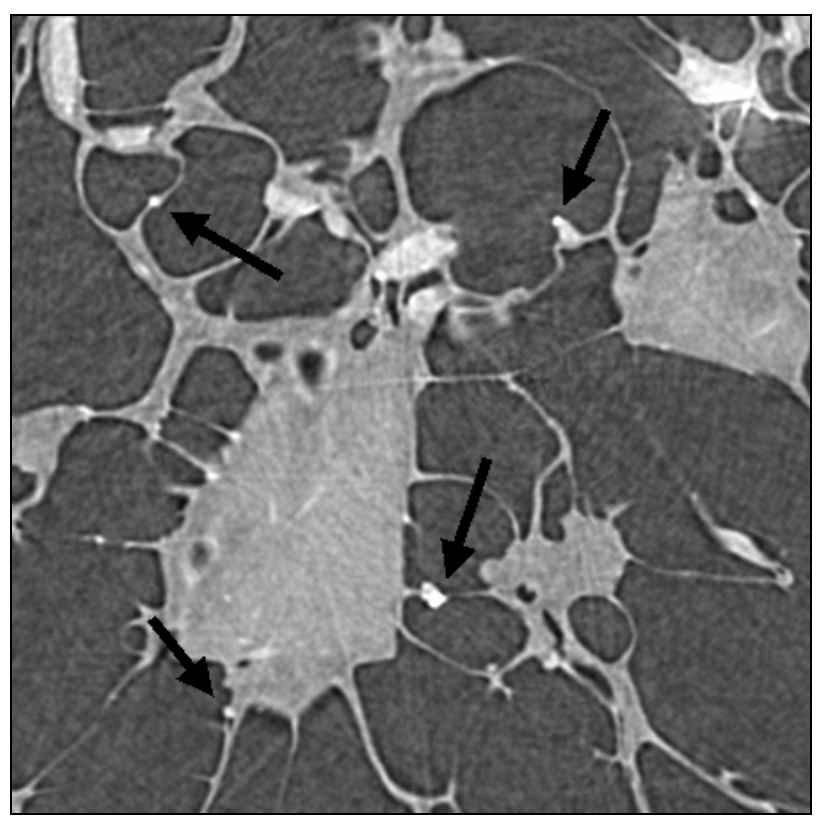

Figure 13

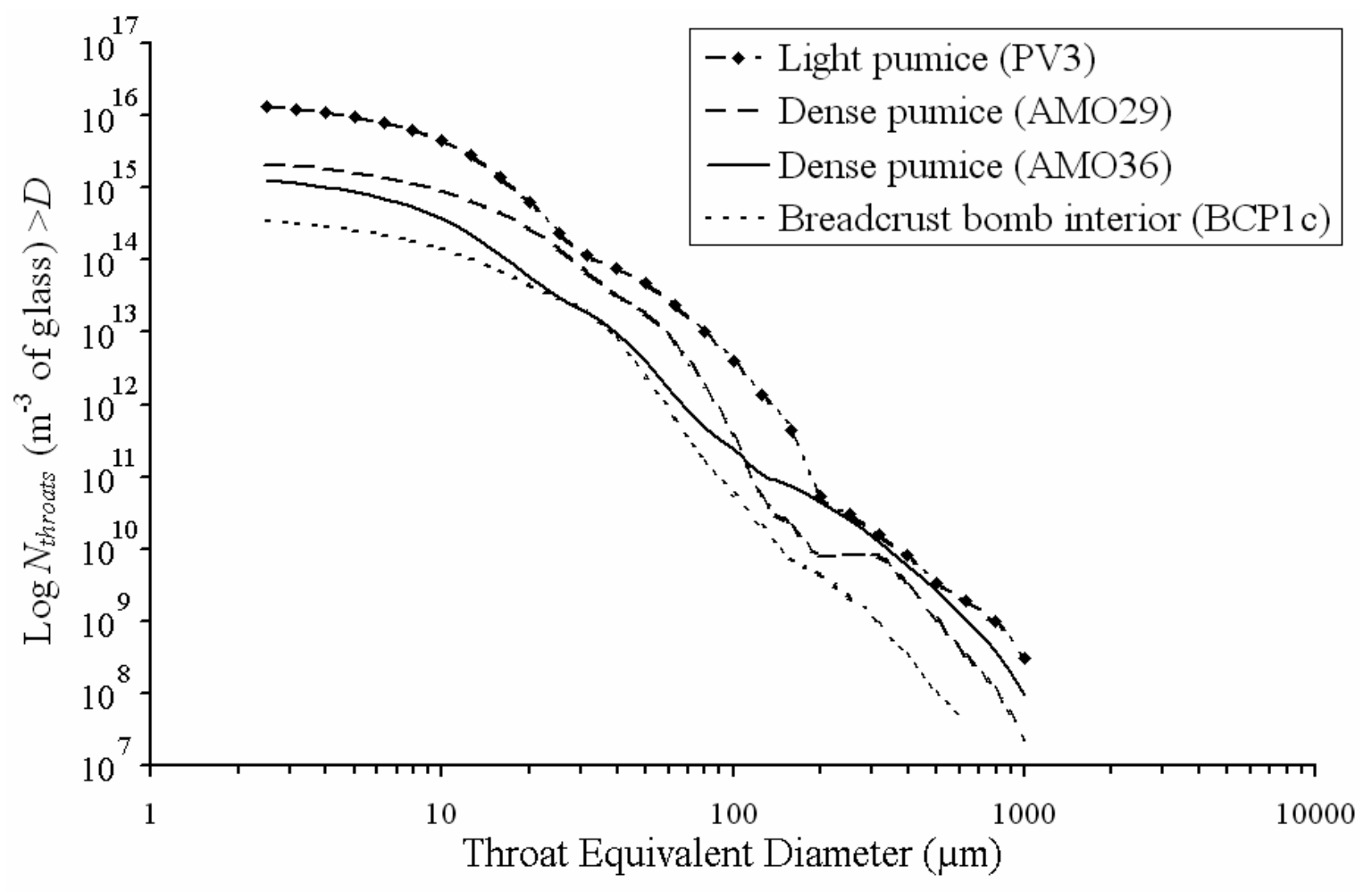


able 1: Results of textural analysis of explosion pyroclasts and comparison with data obtained on the ime samples (Giachetti et al. in press).

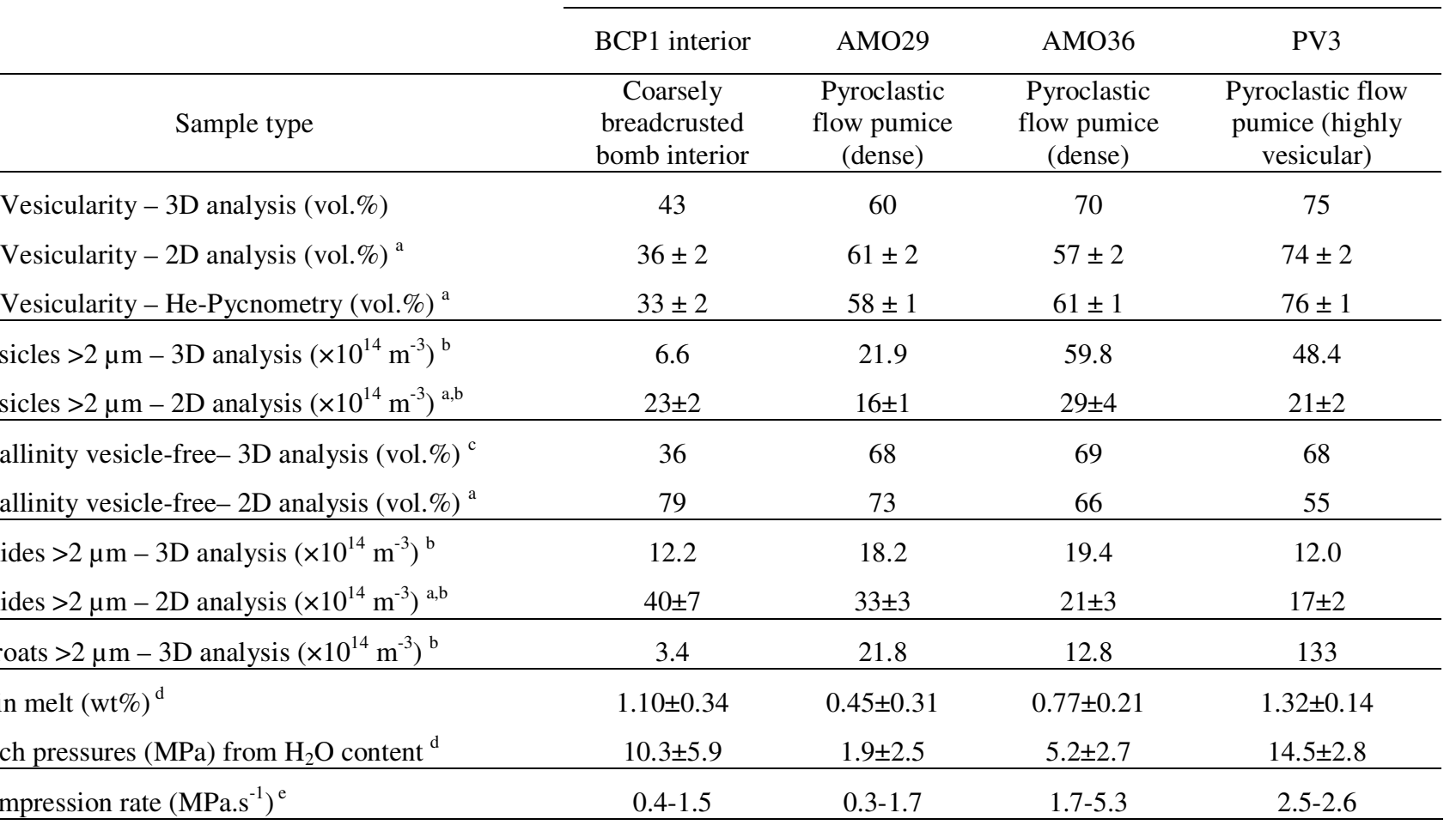

Erom Giachetti et al (in press). $N_{v}$ values recalculated to a $\sim 2 \mu \mathrm{m}$ limit

Glass-referenced

Including microlites (except plagioclase that were not distinguished on the SLS stack images)

From Burgisser et al (submitted)

Using the method of Toramaru (2006) with a temperature of $850^{\circ} \mathrm{C}$ (Devine et al. 2003) and diffusivities lculated by Giachetti et al. (in press) for the same samples. 